\title{
Comparison of functional outcomes between cemented and uncemented bipolar hemiarthroplasty for intracapsular neck femur fractures
}

\author{
Harpreet Singh, Tej S. Rudani*, Malay P. Gandhi, Aliasgar J. Rampurwala
}

Department of Orthopaedics, Geetanjali Medical College and Hospital, Udaipur, Rajasthan, India

Received: 17 December 2019

Revised: 12 February 2020

Accepted: 14 February 2020

*Correspondence:

Dr. Tej S. Rudani,

E-mail: tsr333tej@gmail.com

Copyright: (c) the author(s), publisher and licensee Medip Academy. This is an open-access article distributed under the terms of the Creative Commons Attribution Non-Commercial License, which permits unrestricted non-commercial use, distribution, and reproduction in any medium, provided the original work is properly cited.

\begin{abstract}
Background: The neck of femoral fracture is common and leading fracture in orthopaedic practice. The older age group and female are more to prone to develop this fracture.

Methods: A prospective, clinical observational, analytical comparative study was undertaken in the department of Orthopaedics of Geetanjali Medical College and Hospital in Udaipur, Rajasthan from January 2018 to June 2019.52 adult patients with neck of femur fracture, 26 patients in each group.

Results: In our study, the mean age was 77.72 years. Female preponderance was seen in our study. In our study mean duration of surgery in uncemented group was 65.78 minutes and mean duration of surgery in cemented group was 79.89 minutes. The mean total HHS in our patient was 86.63 with standard deviation of 6.18. Mean HHS for cemented group was 86 and for uncemented group was 87.23 . We found 20 excellent result and 27 good results ( $35.71 \%$ and $51.92 \%$ respectively). We also found 5 fair result $(12.37 \%)$. There were 2 complications, both in cemented group, one had post-operative dislocation and other had a cement reaction.

Conclusions: Both cemented and uncemented hemiarthroplasty are equally good options in the treatment of femoral neck fractures in the elderly. However, it is to be noted that the duration of surgery \& complications, were both less in the uncemented group as compared to cemented hemiarthroplasty group in our study.
\end{abstract}

Keywords: Cemented and uncemented hemiarthroplasty, Femoral neck fractures in the elderly, Female

\section{INTRODUCTION}

Intracapsular fractures of the proximal femur form a major share of fractures in the day to day orthopedic practice. As age increases, bones become weak; and in some cases, even minor trauma can lead to intracapsular neck femur fracture. It is estimated that the incidence of femoral neck fracture with a change of lifestyle will grow from 1.6 million in 1990, as estimated to 6.25 million in 2050 in the world. ${ }^{1}$

The treatment goal is to return the patient to his or her pre-morbid status of function. Management of femoral neck fractures in elderly patients has been controversial. Femoral neck fractures had been considered unsolvable fractures in the older era of orthopedics due to the high rate of associated complications, which included nonunion and avascular necrosis of the femoral head, amongst others. Presently, there are multiple surgical treatment options (cannulated screws, dynamic hip screw systems, blade plates, hemi and total hip arthroplasty) available for their treatment. Intracapsular extent of the fracture, tenuous blood supply to the femoral head going through the neck and difficulty in maintaining fracture reduction have been cited as reasons for failure of fixation. 
Though non-operative treatment of these fractures has been documented, there are currently very few indications for the same (being limited to terminally ill patients or those who are bedridden and non-ambulatory). Surgical treatment has been established as the gold standard; however, the surgical option remains a dilemma. Open reduction and internal fixation have been shown to have a high rate of revision surgery due to nonunion and avascular necrosis.

Hip replacement arthroplasty (partial or total) is emerging as a most viable treatment option, as it allows immediate weight bearing to return elderly patients to activity, eliminates chances of osteonecrosis and nonunion as complications of femoral neck fractures, and reduces the incidence of reoperation compared with internal fixation in the elderly.

Hemiarthroplasty is a common surgery done for displaced fractures of neck of femur. ${ }^{2}$ In case of intracapsular neck femur fracture, incidence of non-union is high and there are more chances of avascular necrosis due to pattern of blood supply .This is one of the reasons for higher preference of hemiarthroplasty as compared to internal fixation in elderly age group. ${ }^{3}$

Hemiarthroplasty can be divided into Unipolar and Bipolar. Unipolar is more associated with a high rate of acetabular erosion. In bipolar prosthesis, hip motion primarily occurs at prosthetic joint and secondarily at metal cartilage interface, so there are less chances of articular wear. ${ }^{4}$ However many studies on the functional outcomes of AMP vs Bipolar prosthesis have shown the end result to be the same.,

Hemiarthroplasty can be either cemented into the femoral canal or uncemented with press- fit technique. ${ }^{6}$ Cementing the prosthesis provides more secure fixation and results in less residual pain and better function. However, the insertion of cement into the medullary canal of the proximal femur increases the morbidity of the operation and carries the risk of cardiovascular collapse. $^{7}$

There is evidence for use of cemented bipolar resulting in greater anchoring and lesser periprosthetic fracture, however, this procedure results in more hemodynamic instability and cardiopulmonary complications such as 'cement reaction'. ${ }^{6-8}$ Some previous studies suggest that cemented bipolar have better prognosis than uncemented bipolar. ${ }^{9}$ Uncemented prosthesis have been said to have a longer life span due to intrinsic bony ingrowth, which provide a long lasting fixation in comparisons to fixation by bone-cement-metal bond which tends to loosen.

This study was thus undertaken with the objective of comparison of functional outcomes between cemented and uncemented bipolar hemiarthroplasty in cases of fracture of intracapsular neck femur.

\section{METHODS}

A prospective, clinical observational \& analytic comparative study was done in an Orthopaedics department of Geetanjali Medical College and Hospital in Udaipur Rajasthan from January 2018 to June 2019. We enrolled 52 patients diagnosed with as intracapsular femur fractures. We excluded those patients who were less than 60 years age, associated other fractures of lower limb, unable to walk before fracture, neoplastic condition, associated hip pathological conditions and neuromuscular diseases.

\section{Intervention}

The decision for cementing was taken before surgery based upon the X-rays and the condition of femoral bone. Patients with better bone indices on X-rays (cortical thickness and proximal femoral morphology) were performed uncemented bipolar hemiarthroplasty as recommended according to dorr's index. ${ }^{10}$ In case the prosthesis was found to be loose intraoperatively, cementing was done in cases of previously decided uncemented group cases. The final decision was thus made intraoperatively.

\section{Operative method}

All surgeries were performed on an elective basis using standard aseptic precautions surgery was performed under spinal or general anesthesia.

Position of the patient: Lateral position with the patient lying on the unaffected side. The skin over the hip was scrubbed with povidone-iodine (7.5\%). The lower extremity from the groin to the toes was draped in sterile towels separately to enable easy manipulation of the limb during surgery.

\section{Approach}

For all patient's posterolateral approach (Moore's Approach).

\section{Incision}

Mark a point $6 \mathrm{~cm}$ distal to PSIS, mark the second point at junction of posterior $1 / 3$ and anterior $2 / 3$ of GT, another point mark at $5 \mathrm{~cm}$ distal to GT along the shaft of femur. Line joining of these marks is incision line. The length of incision may vary according to surgeon's preference. We did the surgery by a mini Moor's approach in which the incision was almost 3 inches. By blunt dissection, fibers of the gluteus maximus were separated. Short external rotators muscle (piriformis, gemelli and obturator internus) were exposed and tagged with vicryl and then cut from GT. Capsulotomy was done. The fractured head and neck of the femur was levered out of the acetabulum and size measured using femoral head gauge. Excision of the remaining 
ligamentum teres and soft tissue was done from acetabulum. The femoral shaft was rasped using a broach (rasp) and prepared for the insertion of the prosthesis. Femoral neck if long was cut with saw, almost $0.5-1 \mathrm{~cm}$ above LT. A single rasp was used in uncemented, and serial rasps used for cemented. In case of cementing, $40 \mathrm{gm}$ of cement used. After preparation of cement, cement inserted into the medullary canal by cement gun. The prosthesis was then inserted into the femoral shaft in about 10-15 degree of anteversion and impacted into the femur. The reduction of the prosthesis was then done using gentle traction of the thigh with external rotation terminally. The hip was tested for full range of movements and stability intra-operatively. After suturing the capsule, the external rotators were sutured, the wound was closed in layers. Sterile dressing applied (Figure 1). Duration of surgery was noted from incision to complete closure.
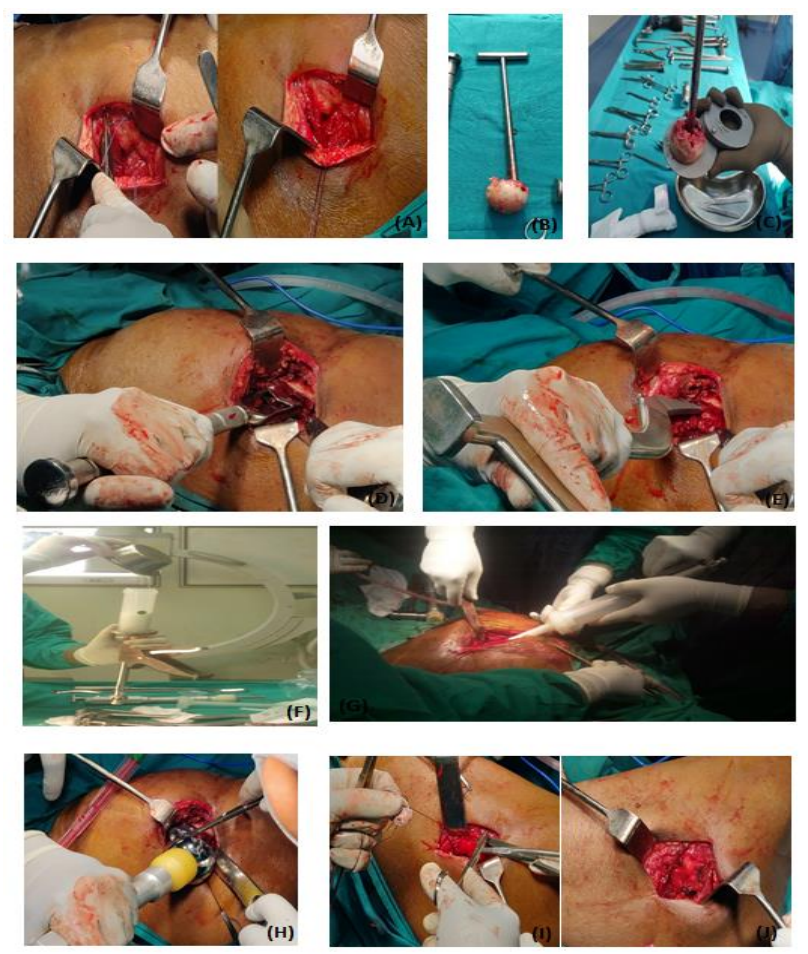

Figure 1: Surgical procedure. (A) Expose the external rotators and tag them with vicryl, (B) extracted Head,

(C) head size measured using femoral head gauge vicryl, (D, E) femoral canal preparation, (F) cementing preparation, $(G)$ inserting cement with cementgun in femoral canal, $(\mathrm{H})$ the prosthesis inserted into the femoral shaft, (I, J) Capsule and external rotators repaired.

\section{Follow up}

For functional assessment, patients were followed at 6 weeks, 3months, 6months and Harris hip score (HHS) was measured. Final functional outcome was graded as following depending on the total HHS at 6 months follow up visit.
Failure: HHS less than 60.

Poor: HHS between 60-69.

Fair: HHS between 70-79.

Good: HHS between 80-89.

Excellent: HHS between 90-100.

\section{Statistical analysis}

The data was entered into the Microsoft excel version 2016 and analyses was done using statistical package for social science version SPSS 25.0. The difference between cemented and uncemented bipolar hemiarthroplasty for intracapsular neck fracture femur in elder age group was calculated using unpaired $t$ test. The difference in frequency of male-female was calculated using Fischer's exact test. Pearson correlation coefficient was calculated to find out any correlation between other variables. $\mathrm{P}$ value less than 0.05 was considered as statistically significant.

\section{RESULTS}

We enrolled a total of 52 patients; 26 patients in each group. In our study, the most common age group was 7180 years of age (mean 72.77). Mean age in cemented group was 72.30 years and mean age in the uncemented group was 72.90 years. The age group in our study was comparable in between the two groups $(\mathrm{p}=0.106)$. We enrolled a total of 21 males and 31 females in our study. Female preponderance $(59.67 \%)$ was seen in our study (Figure 2).

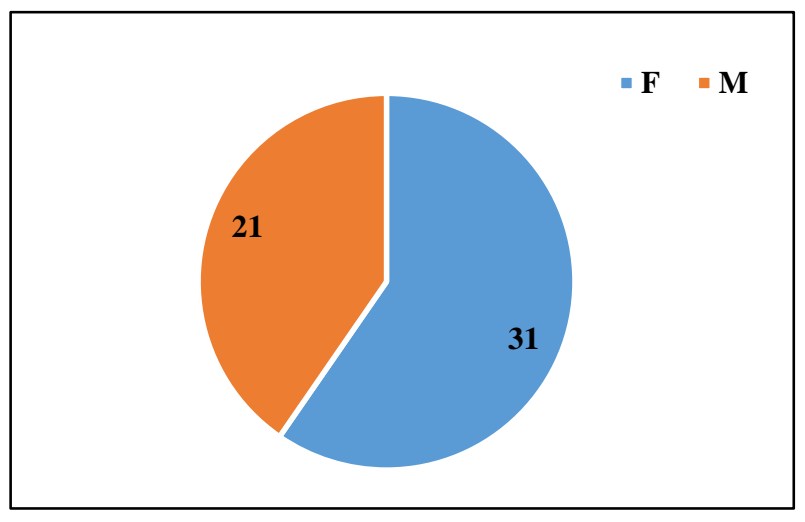

Figure 2: Gender wise distribution in total patients (combine both the groups).

The mean duration of surgery in our study was 71 minutes (range 49-105 $\mathrm{min}$ ). The difference in the operative time between the two groups was statistically significant. ( $\mathrm{P}$ value was less than 0.0001 ) In the cemented group, it was 79.38 minutes and in the uncemented group, it was 64.19 minutes (Figure 3). 


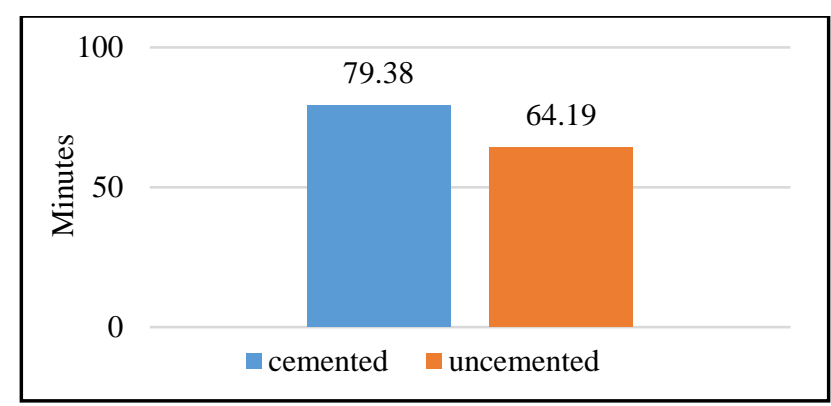

Figure 3: Mean duration of surgery comparing the both the groups.

The mean total HHS in our patients was 86.63 with standard deviation of 6.18. There was no significant difference in total HHS $(\mathrm{p}=0.637)$ between the two groups, at any stage of follow up (Figure 4).

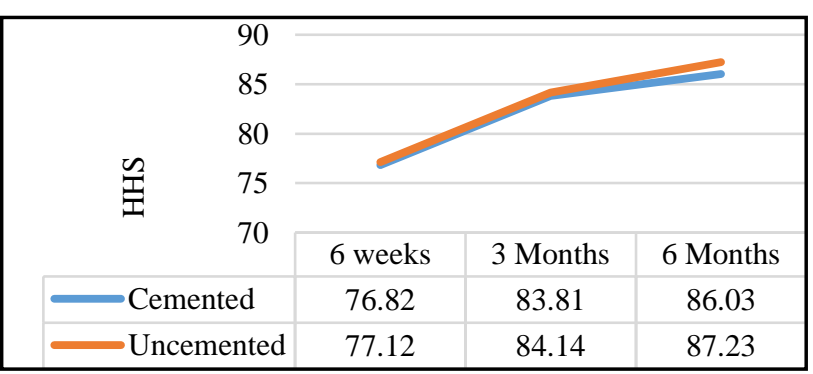

Figure 4: Mean HHS at subsequent follow up.
However, a greater number of uncemented group patient had total HHS score more than 90 (Excellent) as compared to cemented group. On the basis of HHS at last follow up at 6 months, we found results as 20 excellent, 27 good, 5 fairs (Figure 5).

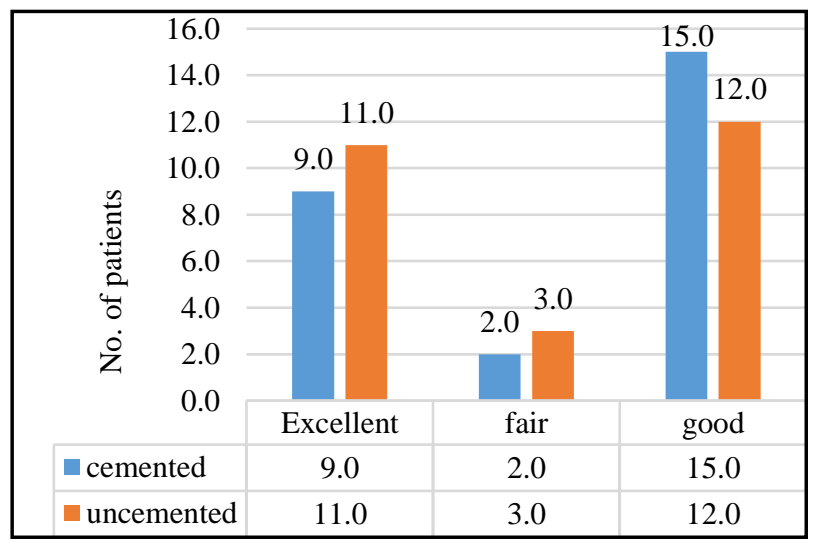

Figure 5: Results based on HHS at final follow up.

There were 2 complications in our study. both patient in cemented group, one had post-operative dislocation on 10th day after surgery due to fall from bed. Other had a cement reaction who had to be put on noninvasive ventilation due to fall in oxygen saturation (Table 1).

Table 1: Differences between two groups.

\begin{tabular}{|c|c|c|c|c|c|c|}
\hline Type & & $\mathbf{N}$ & Mean & Std. deviation & Std. error mean & $P$ value \\
\hline \multirow{2}{*}{ Age (yrs) } & Cemented & 26 & 72.30 & 6.75 & 1.32 & \multirow{2}{*}{0.106} \\
\hline & Uncemented & 26 & 72.84 & 8.96 & 1.75 & \\
\hline \multirow{2}{*}{ Time in min } & Cemented & 26 & 79.38 & 11.21 & 2.20 & \multirow{2}{*}{0.001} \\
\hline & Uncemented & 26 & 64.19 & 11.02 & 2.16 & \\
\hline \multirow{2}{*}{$\begin{array}{l}\text { Total HHS at } 6 \\
\text { weeks }\end{array}$} & Cemented & 26 & 76.82 & 5.68 & 1.10 & \multirow{2}{*}{0.8530} \\
\hline & Uncemented & 26 & 77.12 & 5.93 & 1.5 & \\
\hline \multirow{2}{*}{$\begin{array}{l}\text { Total HHS at } 3 \\
\text { months }\end{array}$} & Cemented & 26 & 83.81 & 6.8 & 1.3 & \multirow{2}{*}{0.8628} \\
\hline & Uncemented & 26 & 84.14 & 6.9 & 1.05 & \\
\hline \multirow{2}{*}{$\begin{array}{l}\text { Total HHS at } 6 \\
\text { months }\end{array}$} & Cemented & 26 & 86.03 & 6.27 & 1.10 & \multirow{2}{*}{0.637} \\
\hline & Uncemented & 26 & 87.23 & 6.14 & 1.51 & \\
\hline
\end{tabular}

\section{DISCUSSION}

We initiated this study with the objective to compare the functional outcomes between cemented and uncemented bipolar hemiarthroplasty for intracapsular neck fracture of femur in elder age group and also to compare the cemented and uncemented bipolar in terms of duration of surgery and complications if any.

In our study, the most common age group was 71-80 years of age and the mean age was 72.77 years. A similar age distribution is reported by other studies such as Moore et al, Lo et al, Kenzora et al, Raia et al. ${ }^{11-17}$
In our study we enrolled a total of 21 males and 31 females in our study. In our study, the intracapsular fracture of the femoral neck was found to be more common in females $(59.67 \%)$. The elderly females are more prone to fracture neck of femur due to osteoporosis. ${ }^{18}$ A similar rate of female preponderance has been reported in several series. ${ }^{19-21}$ However, male preponderance is reported in few series such as D'Arcy and Devas, Mukherjee and Puri, Sanchetti et al, Bavadekar et al. ${ }^{12,22-24}$

The mean duration in our study was 71 minutes (range 49-105 minutes). The mean duration of surgery in uncemented group was 64.19 minutes and in cemented 
group was 79.38 minutes. The difference in operation time in our study seems to be attributable to cementing time. In a study done by Mohabey et al in the uncemented group, the mean duration of surgery was $78.25 \mathrm{~min}$, where as in the cemented group the mean duration of surgery was $111.5 \mathrm{~min} .{ }^{25}$ Wender et al reported duration of $70.2 \mathrm{~min}$ in the uncemented group and $82.6 \mathrm{~min}$ in the cemented group. ${ }^{8}$

The mean total HHS in our patients, in the both the groups combined was 86.63 with standard deviation of 6.18. Over the period of 6 months, both groups showed significant increase in mean HHS at subsequent follows up. At the end of last follow up (6 months), we found that mean HHS for cemented group was 86 and for uncemented group was 87.23 . Uncemented group patients had greater mean HHS as compared to cemented group, but difference was not found to be statistically significant.

However, a greater number of patients with excellent results were seen in uncemented group then the cemented group but the difference was not statistically significant. The results are comparable with the available western and Indian series where hemiarthroplasty was done for the treatment of fracture neck of femur in elderly patients as given in table (Table 2).

There were 2 complications in our study, both in the cemented group. One had post-operative dislocation and the other had cement reaction. Dislocation seen in our study was in a $75 \mathrm{yr}$ old female at 10th post op day, who had undergone cemented hemiarthroplasty. She was discharged on the 4th post op day. On post op day 10 , patient came again to emergency with complain of severe pain in left thigh (operating site) with history of fall from bed. X-ray was done and it was found that she had greater trochanter (GT) fracture along with posterior dislocation. Open reduction along with tension band wiring for GT fracture was done for this patient (Figure 6). Salvatti et al believed that excessive postoperative flexion or rotation with hip adducted is the main cause for dislocation of the prosthesis. ${ }^{26}$ Kenzora et al noted that all six dislocations in their series followed after posterior approach. ${ }^{16}$ However, in our series number of dislocations were not great enough to reach statistical significance.
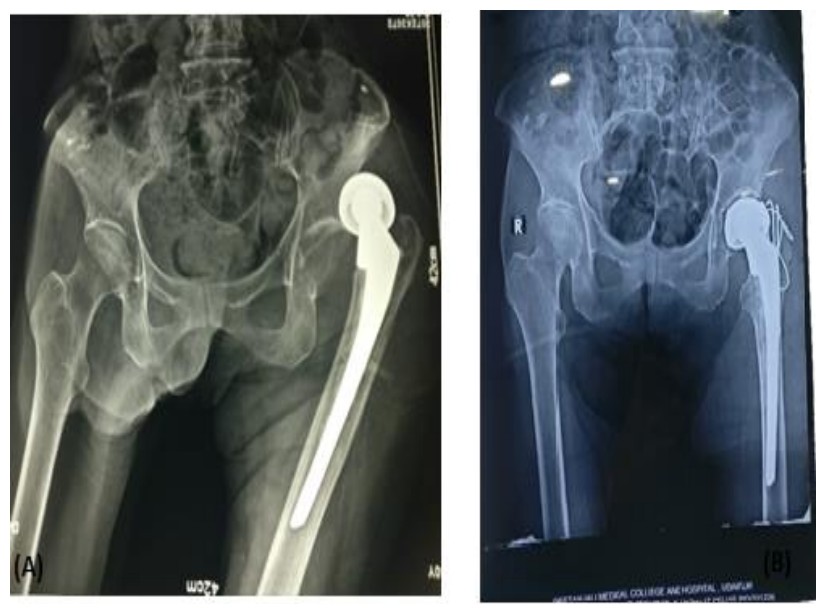

Figure 6: (A) Showing posterior dislocation, (B) Showing ORIF with TBW.

We found one cement reaction in the cemented group. The patient with cement reaction had an intraoperative fall in oxygen saturation and tachycardia. She was managed with noninvasive ventilation. Pitto et al. ${ }^{27}$ in their study, encountered severe embolic events and intraoperative pulmonary impairment during fixation of the cemented femoral component. They concluded that, cementing is believed to have potential physiologically adverse side effects. The major side effects include cardiac arrhythmias and cardio-respiratory collapse, which occasionally occur upon intra operative cement application. Clark et al. found a transient but significant reduction in cardiac output and stroke volume for those receiving cement. ${ }^{28}$

Table 2: Result in various studies.

\begin{tabular}{|c|c|c|c|c|c|}
\hline Investigator & No. of points & Excellent (\%) & Good (\%) & Fair (\%) & Poor $(\%)$ \\
\hline Hinchey Day ${ }^{29}$ & 225 & 52.4 & 20.4 & 10.7 & 16.4 \\
\hline Lanceford $^{30}$ & 210 & 30 & 51 & 9 & 10 \\
\hline Anderson et $\mathbf{a l}^{31}$ & 356 & 51.9 & 28.4 & 14.8 & 4.9 \\
\hline Salvatti et ${ }^{26}$ & 251 & 31 & 26 & 25 & 8 \\
\hline Mukherjee et $\mathrm{al}^{23}$ & 55 & 29 & 49 & 18 & 4 \\
\hline Saxena et al ${ }^{11}$ & 82 & 46.1 & 44.8 & 6.5 & 2.6 \\
\hline Bavadekar et al ${ }^{12}$ & 328 & 60 & 0 & 30 & 10 \\
\hline Arvade et al $^{32}$ & 104 & 70 & 0 & 16 & 14 \\
\hline Our study & 52 & 35.71 & 51.92 & 12.37 & 0 \\
\hline
\end{tabular}

Since in our study, there has been no statically significant difference in the outcome between two groups, one can infer that either of the two procedures could be done with similar results. However, cementing technique needs more surgical time and can results in certain complications like cement reaction. Although insignificant statistically, but the only case of dislocation found in our series was also among the cemented group. 
There are some limitations to note in our study. Radiologic criteria were not taken as a parameter in the follow up. Also, the follow-up period was short (6 months). Another shortcoming was that there could be a bias in patient allocation in the two groups, Since the patients with better bone indices (cortical thickness and proximal femoral morphology) were allotted to the uncemented group. A larger study could be done as a follow up to their study so as to eliminate these shortcomings.

\section{CONCLUSION}

To conclude, both cemented and uncemented hemiarthroplasty are equally good options in the treatment of femoral neck fractures in the elderly. However, it is to be noted that the duration of surgery \& complications, were both less in the uncemented group as compared to cemented hemiarthroplasty group in our study; although there were no statistically significant differences found in the functional outcomes between the two.

Funding: No funding sources

Conflict of interest: None declared

Ethical approval: The study was approved by the institutional ethics committee

\section{REFERENCES}

1. Morshed S, Bozic KJ, Ries MD, Malchau H, Colford JM Jr. Comparison of cemented and uncemented fixation in total hip replacement: a meta-analysis. Acta Orthop. 2007;78(3):315-26.

2. Yurdakul E, Karaaslan F, Korkmaz M, Duygulu F, Baktır A. Is cemented bipolar hemiarthroplasty a safe treatment for femoral neck fracture in elderly patients? Clin Interv Aging. 2015;10:1063-7.

3. Prashanth YS, Niranjan M. Comparative Study of Surgical Management of Fracture Neck of Femur with Cemented Versus Uncemented Bipolar Hemiarthroplasty. J Clin Diagn Res. 2017;11(2):RC17-21.

4. Norrish AR, Rao J, Parker MJ. Prosthesis survivorship and clinical outcome of the Austin Moore hemiarthroplasty: An 8-year mean follow-up of a consecutive series of 500 patients. Injury. 2006;37(8):734-9.

5. Calder SJ, Anderson GH, Jagger C, Harper WM, Gregg PJ. Unipolar or Bipolar prosthesis in displaced intracapsular hip fractures in octogenarians. A Randomised prospective study. J Bone Joint Surg [Br] 1996;78-B:391-4.

6. Donaldson AJ, Thomson HE, Harper NJ, Kenny NW. Bone cement implantation syndrome. $\mathrm{Br} \mathbf{J}$ Anaesth. 2009;102(1):12.

7. Li T, Zhuang Q, Weng X, Zhou L, Bian Y. Cemented versus uncemented hemiarthroplasty for femoral neck fractures in elderly patients: a metaanalysis. PLoS One. 2013; 8(7):68903.
8. Figved W, Opland V, Frihagen F, Jervidalo T, Madsen JE, Nordsletten L. Cemented versus uncemented hemiarthroplasty for displaced femoral neck fractures. Clin Orthop. 2009;467(9):2426-35.

9. Khorami M, Arti H, Aghdam AA. Cemented versus uncemented hemiarthroplasty in patients with displaced femoral neck fractures. Pak J Med Sci. 2016;32(1):44-8.

10. Dorr LD., Faugere MC, Mackel AM, Gruen TA, Bognar B, Mulluche HH. Structural and cellular assessment of bone quality of proximal femur. Bone. 1993;14(3):231-42.

11. Saxena PS, Saraf JK. Moore Prosthesis in fracture neck of femur. Indian J Orthop. 1978;12:138-45.

12. Bavadekar AV, Manelkar KR. Hemiarthroplasty of the hip in the treatment of intracapsular fracture neck of the femur state of the art and an appraisal. Clin Orthop India. 1987;1:43-52.

13. Austin T. Moore: The self-locking metallic hip prosthesis. JBJS. 1957;39A:811-27.

14. Stinchfield FE., Cooperman B, Shea CE. Replacement of the femoral head by Judet or Austin Moore Prosthesis. JBJS. 1957;39A:1043-58.

15. Lo WH, Chen WM, Huang CK, Chen TH, Chiu FY, Chen CM. Bateman bipolar hemiarthroplasty for displaced intracapsular femoral neck fractures. Clin Orthop. 1994;302:75-82.

16. Kenzora JE1, Magaziner J, Hudson J, Hebel JR, Young Y, Hawkes W, et al. Outcome after hemiarthroplasty for fracture neck of femur in elderly. Clini Orthop. 1998;348:51-8.

17. Raia FJ, Chapman CB, Herrera MF, Schweppe MW, Michelsen CB, Rosenwasser MP. Unipolar or bipolar hemiarthroplasty for femoral neck fractures in the elderly. Clin Orthop Relat Res. 2003;414:25965.

18. Choudhary and Mohite. Pathology of fracture neck of femur. Clinical Orthopaedics India. 1987;1:45-8.

19. Terry Canale SMD. Campbell's operative orthopaedics.10th ed. Mosby; 2003: 315-6.

20. Nilsson BE, Spinal osteoporosis and femoral neck fractures. Clinc Orthop. 1970;68:93-5.

21. Sikorski JM, Barrington R. Internal fixation versus hemiarthroplasty for the displaced subcapital fracture of the femur. A prospective randomized study. J Bone Joint Surg Br. 1981;63-B (3):357-61.

22. Acry JD, Devas M. Treatment of fractures of the femoral neck by replacement with the Thompson prosthesis. JBJS. 1976;58B: 279-86.

23. Mukherjee DL, Puri MGHC. Early hemiarthroplasty for fresh fractures of the neck of the femur in geriatric patients. Indian J Surg. 1986;48:77-80.

24. Sancheti KH, Sancheti PK, Shyam AK, Patil S, Dhariwal Q, Joshi R. Primary hemiarthroplasty for unstable osteoporotic intertrochanteric fractures in the elderly: a retrospective case series. Indian J Orthop. 2010;44(4):428-34.

25. Ankush M, Prajakta W, Ravikumar M. Functional outcome of cemented versus uncemented modular 
bipolar hemiarthroplasty in proximal femoral neck fractures. Int J Orthop Sci. 2017;3:609-11.

26. Salvatti EA, Wilson PO. Long term results of femoral head replacements. JBJS. 1972;54A:1355-6.

27. Pitto RP, Koessler M, Kuehle JW. Comparison of fixation of the femoral component without cement and fixation with use of a bone-vacuum cementing technique for the prevention of fat embolism during total hip arthroplasty. A prospective, randomized clinical trial. J Bone Joint Surg Am. 1999;81(6):831-43.

28. Clark DI, Ahmed AB, Baxendale BR, Moran CG. Cardiac output during hemiarthroplasty of the hip. A prospective, controlled trial of cemented and uncemented prostheses. J Bone Joint Surg Br. 2001;83(3):414-8.

29. Hinchey JJ, Day PL. Primary Prosthetic Replacement in Fresh Femoral-Neck Fractures: A review of 294 consecutive cases. JBJS. 1964;46:223-334.

30. Lance FEM. Use of Moore self-locking Vitallium prosthesis in acute fractures of the femoral neck. JBJS. 1965;47A:832-41.

31. Anderson LD, Hamsa WR, Waring TL. Femoralhead prosthesis. A review of three hundred and fifty-six operations and their results. J Bone Joint Surg Am. 1964;46:1049-65.

32. Arwade DJ. A review of internal fixation and prosthetic replacement for fresh fractures of the femoral neck. Clini Orthop India. 1987;1:77-82.

Cite this article as: Singh $\mathrm{H}$, Rudani TS, Gandhi MP, Rampurwala AJ. Comparison of functional outcomes between cemented and uncemented bipolar hemiarthroplasty for intracapsular neck femur fractures. Int J Res Orthop 2020;6:333-9. 